\title{
Neonatal magnesium levels correlate with motor outcomes in premature infants: a long-term retrospective cohort study
}

\section{Elizabeth Doll' ${ }^{1}$, Jacob Wilkes ${ }^{2}$, Lawrence J. Cook ${ }^{3}$, E. Kent Korgenski ${ }^{2}$, Roger G. Faix ${ }^{4}$, Bradley A. Yoder ${ }^{4}$, Rajendu Srivastava ${ }^{2,5}$, Catherine M. T. Sherwin ${ }^{6}$, Michael G. Spigarelli $^{6}$, Erin A. S. Clark ${ }^{7}$ and Joshua L. Bonkowsky ${ }^{1 *}$}

${ }^{1}$ Division of Pediatric Neurology, School of Medicine, University of Utah, Salt Lake City, UT, USA

2 Intermountain Healthcare, Salt Lake City, UT, USA

${ }^{3}$ Division of Critical Care Medicine, School of Medicine, University of Utah, Salt Lake City, UT, USA

${ }^{4}$ Division of Neonatology, School of Medicine, University of Utah, Salt Lake City, UT, USA

${ }^{5}$ Division of Inpatient Medicine, School of Medicine, University of Utah, Salt Lake City, UT, USA

${ }^{6}$ Division of Clinical Pharmacology, Department of Pediatrics, School of Medicine, University of Utah, Salt Lake City, UT, USA

7 Division of Maternal-Fetal Medicine, Department of Obstetrics and Gynecology, School of Medicine, University of Utah, Salt Lake City, UT, USA

\section{Edited by:}

Eugene R. Schnitzler, Loyola

University Medical Center, USA

Reviewed by:

D. Mishra, Maulana Azad Medical College, India

Christopher Mario Inglese, Loyola University Stritch College of

Medicine, USA

*Correspondence:

Joshua L. Bonkowsky, Department of Pediatrics, Division of Pediatric Neurology, University of Utah Health Sciences Center, 295 Chipeta WayMilliams Building, Salt Lake City, UT 84108, USA

e-mail: joshua.bonkowsky@hsc. utah.edu
Objective: Chronic neurological deficits are a significant complication of preterm birth. Magnesium supplementation has been suggested to have neuroprotective function in the developing brain. Our objective was to determine whether higher neonatal serum magnesium levels were associated with better long-term neurodevelopmental outcomes in very-low birth weight infants.

Study Design: A retrospective cohort of 75 preterm infants $(<1500 \mathrm{~g}$, gestational age $<27$ weeks) had follow-up for the outcomes of abnormal motor exam and for epilepsy. Average total serum magnesium level in the neonate during the period of prematurity was the main independent variable assessed, tested using a Wilcoxon rank-sum test.

Results: Higher average serum magnesium level was associated with a statistically significant decreased risk for abnormal motor exam $(p=0.037)$. A lower risk for epilepsy in the group with higher magnesium level did not reach statistical significance $(p=0.06)$.

Conclusion: This study demonstrates a correlation between higher neonatal magnesium levels and decreased risk for long-term abnormal motor exam. Larger studies are needed to evaluate the hypothesis that higher neonatal magnesium levels can improve long-term neurodevelopmental outcomes.

Keywords: magnesium, prematurity, neurological, VLBW, neuroprotection, neonate

\section{INTRODUCTION}

Preterm birth can lead to a wide range of motor and intellectual disabilities affecting up to $35 \%$ of survivors (1-4). Very-low birth weight (VLBW) infants with birth weight less than 1500 g have elevated rates of cerebral palsy, epilepsy, autism, intellectual disability, and behavioral problems $(5,6)$. While survival rates have improved dramatically for premature infants (7), neurodevelopmental outcomes have not (8). Despite efforts to reduce preterm birth, the rate has remained relatively stable over the last few decades and was $11.7 \%$ in the United States in 2011 (9).

The neurodevelopmental problems in prematurely born infants are caused by a variety of complex pathophysiological mechanisms $(10,11)$ with few therapeutic options (12). Further, the complications of preterm birth are now also recognized to damage both gray matter and axon tracts and to lead to impaired neurodevelopment (13-17).

Abbreviations: CNS, central nervous system; EDW, enterprise data warehouse; $\mathrm{IH}$, intermountain healthcare; VLBW, very-low birth weight.
Magnesium sulfate administered antenatally has been found to reduce rates of cerebral palsy when given prior to preterm birth (18-20). Magnesium has also been found in small studies to improve neurodevelopmental outcomes in term infants with birth asphyxia (21-24). Further, several animal model studies suggest that magnesium could play neuroprotective roles in the developing vertebrate CNS (25-27).

Our hypothesis was that postnatal magnesium could serve a neuroprotective role in the developing premature brain. Magnetic resonance imaging (MRI) data suggest that longer exposure of premature infants to the extrauterine environment results in increasing impairments of CNS connectivity (28). We posited that magnesium could help protect connectivity development of premature infants, and that higher magnesium levels throughout the premature period could be neuroprotective.

To address this hypothesis, we evaluated serum magnesium levels in VLBW infants and compared these with long-term neurodevelopmental outcomes, specifically epilepsy, and abnormal motor exam. We recorded magnesium levels during the initial 
hospitalization, for the time period when the infants were still premature (less than 37 weeks gestation). The objective of our study was to determine whether higher neonatal magnesium levels are associated with improved long-term neurological outcomes.

\section{MATERIALS AND METHODS ETHICS STATEMENT}

This study was approved by the Institutional Review Boards at the University of Utah and Intermountain Healthcare (IH). Data were anonymously collected and analyzed with no identifying information, and a waiver of informed consent was obtained.

\section{STUDY DESIGN AND DATA EXTRACTION}

Data extraction and analysis were performed retrospectively in a cohort of premature infants born at an IH hospital and who were seen in follow-up in the Utah State Department of Health Neonatal Follow-up Program. The cohort consisted of a consecutive series of 107 infants born between 1/1/06 through 12/31/10, with birth weights $<1500 \mathrm{~g}$ and up to $26^{6 / 7}$ weeks gestational age (Table 1 ). Five patients were lost to follow-up; 27 patients had incomplete or missing data and were not included in analysis (Table 2). Serum magnesium levels were those drawn during the initial hospitalization up through the end of the premature period; defined as less than 37 weeks gestation. IH is a large, vertically integrated not-forprofit health care system in the Intermountain West encompassing 23 hospitals including the single children's hospital. Antenatal, perinatal, and follow-up data were extracted for each patient in the cohort from the Enterprise Data Warehouse (EDW) maintained by IH.

Table 1 | Demographic characteristics of the study group

\begin{tabular}{|c|c|}
\hline Characteristic & Study cohort $n(\%)$ \\
\hline Gender (male) & $44(59 \%)$ \\
\hline \multicolumn{2}{|l|}{ Ethnicity } \\
\hline Caucasian & $51(68 \%)$ \\
\hline Hispanic & $8(11 \%)$ \\
\hline Pacific-Islander & $2(3 \%)$ \\
\hline African-American & $2(3 \%)$ \\
\hline Native American & $1(1 \%)$ \\
\hline Asian & $3(4 \%)$ \\
\hline Unknown & $8(11 \%)$ \\
\hline Multiple gestation & $4(5 \%)$ \\
\hline Antenatal magnesium & $20(27 \%)$ \\
\hline \multicolumn{2}{|l|}{ Gestational age (weeks) } \\
\hline Mean (SD; range) & $25.8(1.2 ; 22-27)$ \\
\hline Median (Q1, Q3) & $26.0(25.0,26.7)$ \\
\hline \multicolumn{2}{|l|}{ Birth weight (g) } \\
\hline Mean (SD; range) & $817.3(213 ; 450-1410)$ \\
\hline Median (Q1, Q3) & $770(660,930)$ \\
\hline \multicolumn{2}{|c|}{ Length of mechanical ventilation (days) } \\
\hline Mean (SD; range) & $12.1(21.6,0-97)$ \\
\hline Median (Q1, Q3) & $3,(2,6)$ \\
\hline
\end{tabular}

Study group, $n=75$.

SD, standard deviation; g, grams; $Q 1$ and Q3, first and third quartiles.
We queried the EDW using unique identifiers assigned to each of the cohort infants for the period including up to 5 years after birth. Data collected from the EDW included name; date of birth; gender; ethnicity; birth weight; birth head circumference; gestational age; presence of multiple gestation; administration of corticosteroids prior to delivery; administration of magnesium sulfate prior to delivery; mode of delivery; length of hospitalization; all neonatal total serum magnesium levels; days requiring mechanical ventilation; and the presence of seizures (ICD-9 codes 779.0 and 345.x). Of note, diagnoses of seizures at any time during the NICU hospitalization were excluded, as was the diagnosis of febrile seizures. Data extracted manually from the neurodevelopmental assessment at age 20-36 months included neurological exam for hypotonia, spasticity, and/or cerebral palsy.

Long-term follow-up for infants was assessed and recorded using two sources. First, for the outcome of the abnormal motor exam, data from the Utah State Department of Health Neonatal Follow-up Program were obtained. A standardized neurological motor exam was performed by a developmental pediatrician or pediatric neurologist when the infant was between 20 and 36 months of age. An abnormal motor exam was defined as cerebral palsy (including hypertonia/spasticity or dystonia), hypotonia, or spasticity. Second, for the outcome of epilepsy, we followed the infants for up to 5 years after birth using the EDW. We defined epilepsy as any encounter that had a record of the patient having had a seizure and for which the patient was placed on an anti-epileptic drug. The outcome of epilepsy excluded seizures that occurred solely during the NICU hospitalization; and febrile seizures.

We limited the time period of magnesium levels used in our analysis to that of prematurity only; i.e., less than 37 weeks gestation. In the IH system, the lower and upper limits of magnesium levels are defined as from 1.2 to $2.8 \mathrm{mg} / \mathrm{dL}$, respectively.

\begin{tabular}{|c|c|}
\hline Characteristic & Excluded cohort $n(\%)$ \\
\hline Gender (male) & $9(33 \%)$ \\
\hline \multicolumn{2}{|l|}{ Ethnicity } \\
\hline Caucasian & $20(71.4 \%)$ \\
\hline Hispanic & $3(11 \%)$ \\
\hline Pacific-Islander & $0(0 \%)$ \\
\hline African-American & $1(3.6 \%)$ \\
\hline Native American & $0(0 \%)$ \\
\hline Asian & $0(0 \%)$ \\
\hline Unknown & $3(14 \%)$ \\
\hline Multiple gestation & $4(15 \%)$ \\
\hline \multicolumn{2}{|c|}{ Gestational age (weeks) } \\
\hline Mean (range) & $25.7(23.8-27)$ \\
\hline \multicolumn{2}{|l|}{ Birth weight (g) } \\
\hline Average & 789 \\
\hline Range & $500-1110$ \\
\hline \multicolumn{2}{|c|}{ Length of mechanical ventilation (days) } \\
\hline Mean (range) & $8.6(0-45)$ \\
\hline
\end{tabular}




\section{STATISTICAL ANALYSIS}

Statistical analyses were performed using SAS Analytics Pro version 9.3 (SAS Inc.). Descriptive statistics were used to characterize the study cohort. Wilcoxon Rank-Sum tests were used to compare magnesium levels for the outcomes of seizures and of composite abnormal motor exams. An alpha level of 0.05 was used to determine statistical significance; $p$-values were two-sided. For multivariate logistic regression analysis we modeled birth weight and magnesium levels by analysis of quartiles.

\section{RESULTS}

We collected all total serum magnesium levels $(n=223)$ drawn on a cohort of 75 very-low birth weight (VLBW) infants during their initial, post-birth hospitalization (Table 1). There were no deaths in the study cohort. On average infants had their magnesium levels checked three times, but the number of magnesium levels checked ranged from 1 to 17 times (Table 3). Average total serum magnesium level was $2.4 \mathrm{mg} / \mathrm{dL}$ with a range of $1.1-5.8 \mathrm{mg} / \mathrm{dL}$.

There were $10(13 \%)$ infants that had epilepsy, and $24(32 \%)$ with abnormal motor exams. Abnormal motor exam, which was defined as the presence of cerebral palsy, hypotonia, or spasticity, was assessed between 20 and 36 months after birth. The outcome of epilepsy was assessed for by following patient outcomes for up to 5 years after birth. Importantly, to avoid inflating epilepsy rates, "epilepsy" was defined for the purpose of outcomes by excluding seizures which occurred in the neonatal period only, and by excluding febrile seizures.

All infants with epilepsy also had an abnormal motor exam. We found that children with abnormal motor exams had statistically significant lower magnesium levels in the neonatal period ( $p=0.037$ ) (Table 4; Figure 1A). Infants who went on to develop epilepsy had lower average minimum magnesium levels in the neonatal period, but this was not statistically significant $(p=0.060)$ (Table 4; Figure 1B). We also performed logistic regression analyses that included birth weight and magnesium level. While they showed a trend toward lower magnesium levels associated with increased risk for abnormal motor outcome or for epilepsy, the sample size was underpowered and did not show statistically significant differences (Table 5).

We also considered whether there might be potential clinical history confounders, by examining whether there were other clinical characteristics associated with high or low magnesium levels

\section{Table 3 | Characteristics of serum magnesium testing}

\begin{tabular}{ll}
\hline Characteristic & \\
Average number of draws/infant & 3 \\
Range number of draws/infant & $1-17$ \\
Age at first draw (DOL) (avg.) & 3.5 \\
Range of age for first draw (DOL) & $0-56$ \\
Proportion of draws <3 DOL & $36 \%$ \\
Serum levels (mg/dl) & \\
Mean (SD; range) & $2.4(0.83 ; 1.1-5.8)$ \\
Median & $2.2(1.9,2.7)$ \\
Mode & 2.1
\end{tabular}

$D O L$, day of life; $S D$, standard deviation. (high defined as $2.3 \mathrm{mg} / \mathrm{dL}$ or above, low $2.2 \mathrm{mg} / \mathrm{dL}$ and below) (Table 6), and by analyzing whether other clinical characteristics were associated with the outcomes of epilepsy or abnormal motor outcome (Table 7). While there were some differences between the groups, there was not a consistent trend.

\section{DISCUSSION}

We examined the correlation between postnatal magnesium levels and neurodevelopmental outcomes in premature infants. While prenatal magnesium administration has been associated with a decreased risk of cerebral palsy (18-20), our study demonstrates that postnatal serum magnesium levels in VLBW infants may be associated with improved neurodevelopmental outcomes. Specifically, higher serum magnesium levels in preterm infants were associated with lower rates of an abnormal motor exam (spasticity, cerebral palsy, or hypotonia). There was a lower risk for epilepsy, but this finding was not statistically significant.

Our study raises the possibility that there may be a broader window of opportunity for magnesium administration in premature infants to help improve neurodevelopmental outcomes. That is, perhaps magnesium supplementation could also be considered in premature infants and not only in mothers at risk for preterm birth. Use of magnesium sulfate would have to be balanced with concerns for potential adverse side-effects in premature infants $(29,30)$. Another issue requiring further study will be research on the mechanism(s) of potential neuroprotection. This is because most infants had a magnesium level in the "normal" range, and because there was significant overlap in the magnesium levels of infants with normal outcomes compared to infants who developed epilepsy or abnormal motor outcomes (Figure 1).

Animal model data show a neuroprotective role for magnesium against injury in the developing CNS (25-27). Further, in term infants with birth asphyxia a potentially protective role has been suggested for magnesium (21-24). There are multiple potential mechanism(s) by which magnesium could exert neuroprotective effects. Magnesium can block calcium influx through the $\mathrm{N}$ methyl-D-aspartate (NMDA) receptor channel and thereby reduce glutamate excitotoxicity; can reduce inflammatory cytokine and free radical production; can stabilize membranes; and can normalize blood pressure fluctuations (31-33). Magnesium can also prevent activation of the hypoxia inducible factor $1 \alpha$ (HIF $1 \alpha)$ pathway that leads to axon pathfinding errors (27).

Table 4 | Wilcoxon rank-sum tests for epilepsy and for abnormal motor exam.

\begin{tabular}{llll}
\hline Magnesium level & \multicolumn{1}{c}{ Outcome } & $p$-Value \\
\hline Epilepsy & & & \\
Median & No $(n=65)$ & Yes $(n=10)$ & \\
Abnormal motor exam & 2.30 & 1.95 & 0.060 \\
& No $(n=51)$ & Yes $(n=24)$ & \\
Median & 2.30 & 2.00 & 0.037
\end{tabular}

The number of patients with the outcome is indicated in parentheses. Magnesium levels are milligrams per deciliter. Two-sided p-values are given. 


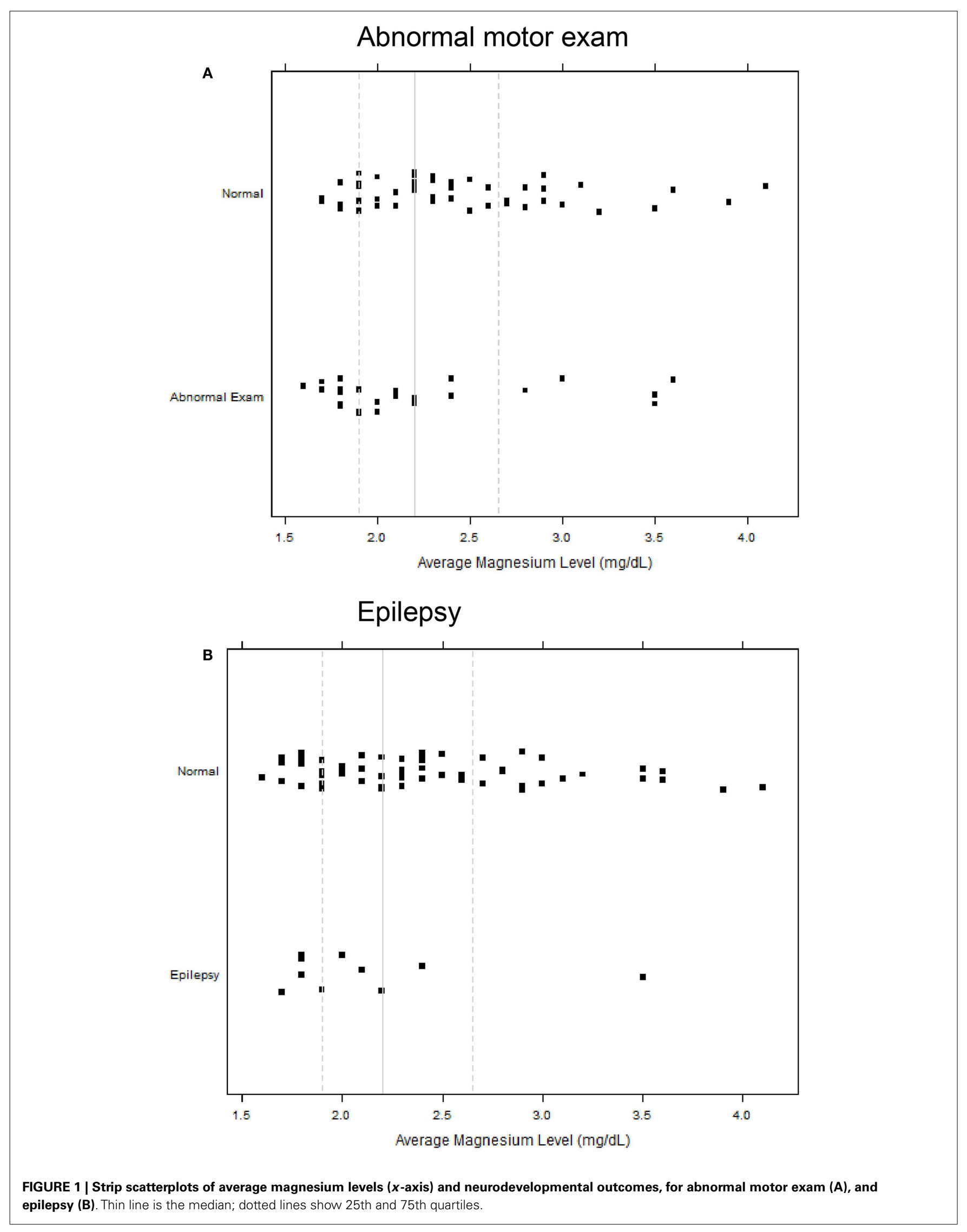


Table 5 | Logistic regression results; (A) Multivariable regression analysis for the outcome of seizures, analyzed for birth weight and magnesium levels; (B) Multivariable regression analysis for the outcome of abnormal motor exam, analyzed for birth weight, and magnesium levels

\section{(A)}

Average magnesium level quartile by seizures

Quartile of Mg level

No Yes

Q1, Mg level $\leq 1.9$

$17(77 \%) \quad 5(23 \%)$

Q2, $1.9<\mathrm{Mg}$ level $\leq 2.2$

$14(82 \%) \quad 3(18 \%)$

Q3, $2.2<\mathrm{Mg}$ level $\leq 2.7$

$18(95 \%) \quad 1(5 \%)$

Q4, Mg level $>2.7$

$16(94 \%) \quad 1(6 \%)$

Birth weight quartile by seizures

Quartile of Mg level

Q1, Birth weight $\leq 660$

No Yes

Q2, $660<$ Birth weight $\leq 770$

$19(95 \%) \quad 1(5 \%)$

Q3, $770<$ Birth weight $\leq 930$

$14(78 \%) \quad 4(22 \%)$

$16(84 \%) \quad 3(16 \%)$

Q4, Birth weight $>930$

$16(89 \%) \quad 2(11 \%)$

\begin{tabular}{|c|c|c|c|c|}
\hline Parameter & Estimate & LCL & UCL & $p$-Value \\
\hline \multicolumn{5}{|c|}{ Birth weight (04 = Ref) } \\
\hline Q1 & 1.00 & 0.22 & 4.51 & 1.00 \\
\hline $\mathrm{Q} 2$ & 1.34 & 0.31 & 5.89 & 0.696 \\
\hline Q3 & 1.15 & 0.28 & 4.76 & 0.842 \\
\hline \multicolumn{5}{|c|}{ Milligrams level (Q4 = Ref) } \\
\hline Q1 & 2.40 & 0.62 & 9.24 & 0.842 \\
\hline $\mathrm{Q} 2$ & 1.30 & 0.30 & 5.61 & 0.725 \\
\hline Q3 & 0.28 & 0.05 & 1.72 & 0.169 \\
\hline
\end{tabular}

Average magnesium level quartile by abnormal motor scores

Quartile of milligram level

Q1, Mg level $\leq 1.9$

No Yes

Q2, $1.9<\mathrm{Mg}$ level $\leq 2.2$

$11(50 \%) \quad 11(50 \%)$

Q3, $2.2<\mathrm{Mg}$ level $\leq 2.7$

$11(65 \%) \quad 6(35 \%)$

$17(89 \%) \quad 2(11 \%)$

$12(71 \%) \quad 5(29 \%)$

Q4, Mg level $>2.7$

No Yes

Quartile of milligrams Leve

No Yes

Q1, Birth weight $\leq 660$

$17(77 \%) \quad 5(23 \%)$

$\begin{array}{lll}\text { Q2, } 660<\text { Birth weight } \leq 770 & 14(82 \%) & 3(18 \%) \\ \text { Q3, } 770<\text { Birth weight } \leq 930 & 18(95 \%) & 1(5 \%)\end{array}$

Q4, Birth weight $>930 \quad 16(94 \%) \quad 1(6 \%)$

\begin{tabular}{|c|c|c|c|c|}
\hline Parameter & Estimate & LCL & UCL & $p$-Value \\
\hline \multicolumn{5}{|c|}{ Birth weight (04= Ref) } \\
\hline Q1 & 0.61 & 0.05 & 7.77 & 0.700 \\
\hline Q2 & 3.10 & 0.45 & 21.39 & 0.251 \\
\hline Q3 & 1.46 & 0.20 & 10.50 & 0.707 \\
\hline \multicolumn{5}{|c|}{ Milligrams level (Q4= Ref) } \\
\hline Q1 & 4.82 & 0.48 & 47.91 & 0.180 \\
\hline Q2 & 3.51 & 0.31 & 39.89 & 0.311 \\
\hline Q3 & 0.86 & 0.047 & 15.59 & 0.917 \\
\hline
\end{tabular}

LCL, 95\% lower confidence limit; UCL, 95\% upper confidence limit; Q1, first quartile.

(A) Fisher's exact $p$-value $=0.316$; Fisher's exact $p$-value $=0.891$.

(B) Fisher's exact $p$-Value $=0.058$; Fisher's exact $p$-value $=0.434$

Limitations of this study included sample size, retrospective data collection, and missing follow-up for some infants. While the presence of an abnormal neuro-motor exam can be determined by age 20 months as was done in this study, a more extensive longitudinal study with objective scoring, such as using the Bailey Scale of Infant Development, would provide more 
Table 6 | Comparison of clinical variables in "low" and "high" magnesium patient groups.

\begin{tabular}{lll}
\hline Clinical variable & Low magnesium & High magnesium \\
\hline Male gender & $57 \%$ & $59 \%$ \\
Caucasian & $71 \%$ & $68 \%$ \\
Birth weight & $872 \mathrm{~g}$ & $755 \mathrm{~g}$ \\
Gestational age & 25.9 weeks & 25.7 weeks \\
Maternal age & 27.5 years & 28.4 years \\
Maternal parity & 3.1 & 2.6 \\
Maternal smoking & $29 \%$ & $14 \%$ \\
Medicaid & $36 \%$ & $38 \%$ \\
Maternal diabetes & 0 & $5.4 \%$ \\
Maternal hypertension & $7.1 \%$ & $32 \%$ \\
Maternal drug use & $7.1 \%$ & 0 \\
Multiple gestation & 0 & $10.8 \%$ \\
Antepartum hemorrhage & $29 \%$ & $16 \%$ \\
Chorioamnionitis & $4.8 \%$ & $2.7 \%$ \\
Steroids pre-delivery & $83 \%$ & $73 \%$ \\
Ventilator days & 12.3 & 10.9 \\
ECMO & $0 \%$ & $0 \%$ \\
Hydrocephalus & $7.1 \%$ & $8.1 \%$ \\
NEC & $17 \%$ & $11 \%$ \\
IVH (Grade II, III, IV) & $40 \%$ & $27 \%$ \\
Length of stay & 109 days & 104 days \\
\hline
\end{tabular}

"Low" magnesium was defined as average magnesium level of $2.2 \mathrm{mg} / \mathrm{dL}$ or lower; "high" was defined as $2.3 \mathrm{mg} / \mathrm{dL}$ or higher.

$E C M O$, extra-corporeal membrane oxygenation; $I V H$, intraventricular hemorrhage; NEC, necrotizing enterocolitis.

reliable outcomes data. We excluded 32 infants from our analysis because of incomplete data, including a lack of magnesium levels. The small sample size also led to limitations on performing multivariate regression analyzes (34). Another bias could arise because timing of magnesium level blood draws were not evenly distributed in the different infants; and were not distributed evenly across the hospitalization. Because of the sample size, we were not able to control for multiple factors that could play an important role in the outcomes, such as intraventricular hemorrhage; maternal steroid or magnesium administration; or birth weight, among others. Pharmacokinetics and pharmacodynamics of serum magnesium can be affected by both endogenous and iatrogenic factors, including medications and calcium metabolism. Our study did not address these issues. In fact, normative premature infant magnesium levels, and effects of maternal magnesium administration on neonatal levels, are under active study $(35,36)$, and are important subjects for future research.

Our pilot findings raise the possibility that magnesium levels during a critical developmental time window could affect neurological outcome. In the U.S. 500,000 births each year are premature, while worldwide it is estimated that 12.9 million infants yearly are born before 37 weeks gestation $(9,37$, 38). This significant burden of prematurity, with its attendant risks for adverse neurodevelopmental outcomes, warrants further
Table 7 | Comparison of clinical variables and the outcomes for epilepsy or abnormal motor exam.

\begin{tabular}{lll}
\hline Clinical variable & Epilepsy & Abnormal motor \\
\hline & $+/-$ & $+/-$ \\
Male gender & $90 / 57 \%$ & $65 / 55 \%$ \\
Caucasian & $60 / 71 \%$ & $69 / 70 \%$ \\
Birth weight & $832 / 815 \mathrm{~g}$ & $833 / 810 \mathrm{~g}$ \\
Gestational age (days) & $179 / 181$ & $180 / 181$ \\
Maternal age & $25.5 / 28.3$ & $25.7 / 29$ \\
Maternal parity & $4.2 / 2.7$ & $2.47 / 1.74$ \\
Maternal smoking & $10 / 23 \%$ & $12 / 26 \%$ \\
Medicaid & $60 / 33 \%$ & $46 / 32 \%$ \\
Maternal diabetes & $0 / 2.9 \%$ & $0 / 3.8 \%$ \\
Maternal hypertension & $0 / 21.7 \%$ & $12 / 23 \%$ \\
Maternal drug use & $0 / 4.3 \%$ & $0 / 5.7 \%$ \\
Multiple gestation & $0 / 5.8 \%$ & $0 / 7.5 \%$ \\
Antepartum hemorrhage & $50 / 19 \%$ & $31 / 19 \%$ \\
Chorioamnionitis & $0 / 4.3 \%$ & $3.8 / 5.7 \%$ \\
Mg pre-delivery & $20 / 35 \%$ & $19 / 28 \%$ \\
Steroids pre-delivery & $90 / 77 \%$ & $88 / 74 \%$ \\
Ventilator days & $19 / 11$ & $17 / 9.2$ \\
ECMO & $0 / 0 \%$ & $0 / 0 \%$ \\
Hydrocephalus & $20 / 5.8 \%$ & $15 / 3.8 \%$ \\
NEC & $10 / 14 \%$ & $12 / 15 \%$ \\
IVH (Grade II, III, IV) & $50 / 32$ & $50 / 26$ \\
Length of stay (days) & $132 / 103$ & $123 / 98$ \\
\hline & & \\
\hline
\end{tabular}

+, diagnosis present; -, diagnosis absent (e.g., normal). ECMO, extra-corporeal membrane oxygenation; IVH, intraventricular hemorrhage; NEC, necrotizing enterocolitis.

investigations into potential neuroprotective roles for magnesium after preterm birth.

\section{ACKNOWLEDGMENTS}

We thank F. Balch and X. Sheng for helpful discussions. Sources of financial support: RGF was funded in part by NIH grant U10 HD053124 from the Eunice Kennedy Shriver National Institute of Child Health and Human Development. EASC was funded in part by NIH grant K23 HD061910 from the Eunice Kennedy Shriver National Institute of Child Health and Human Development. JLB was funded in part by NIH grants K08 DA024753 and DP2 MH100008, from the March of Dimes Foundation, and from the Primary Children's Medical Center Foundation.

\section{REFERENCES}

1. Vohr BR, Wright LL, Dusick AM, Mele L, Verter J, Steichen JJ, et al. Neurodevelopmental and functional outcomes of extremely low birth weight infants in the National Institute of Child Health and Human Development Neonatal Research Network, 1993-1994. Pediatrics (2000) 105:1216-26. doi:10.1542/peds.105.6. 1216

2. Bass JL, Corwin M, Gozal D, Moore C, Nishida H, Parker S, et al. The effect of chronic or intermittent hypoxia on cognition in childhood: a review of the evidence. Pediatrics (2004) 114:805-16. doi:10.1542/peds.2004-0227

3. Barrett RD, Bennet L, Davidson J, Dean JM, George S, Emerald BS, et al. Destruction and reconstruction: hypoxia and the developing brain. Birth Defects Res $C$ Embryo Today (2007) 81:163-76. doi:10.1002/bdrc.20095 
4. Saigal S, Doyle LW. An overview of mortality and sequelae of preterm birth from infancy to adulthood. Lancet (2008) 371:261-9. doi:10.1016/S0140-6736(08) 60136-1

5. Horwood LJ, Mogridge N, Darlow BA. Cognitive, educational, and behavioural outcomes at 7 to 8 years in a national very low birthweight cohort. Arch Dis Child Fetal Neonatal Ed (1998) 79:F12-20. doi:10.1136/fn.79.1.F12

6. de Kieviet JF, Piek JP, Aarnoudse-Moens CS, Oosterlaan J. Motor development in very preterm and very low-birth-weight children from birth to adolescence: a meta-analysis. JAMA (2009) 302:2235-42. doi:10.1001/jama.2009.1708

7. Fanaroff AA, Stoll BJ, Wright LL, Carlo WA, Ehrenkranz RA, Stark AR, et al. Trends in neonatal morbidity and mortality for very low birthweight infants. Am J Obstet Gynecol (2007) 196(2):147.e1-8.

8. Hintz SR, Kendrick DE, Wilson-Costello DE, Das A, Bell EF, Vohr BR, et al. Early-childhood neurodevelopmental outcomes are not improving for infants born at $<25$ weeks' gestational age. Pediatrics (2011) 127:62-70. doi:10.1542/ peds.2010-1150

9. Hamilton BE, Hoyert DL, Martin JA, Strobino DM, Guyer B. Annual summary of vital statistics: 2010-2011. Pediatrics (2013) 131:548-58. doi:10.1542/peds. 2012-3769

10. Inder TE, Volpe JJ. Mechanisms of perinatal brain injury. Semin Neonatol (2000) 5:3-16. doi:10.1053/siny.1999.0112

11. Ferriero DM. Neonatal brain injury. N Engl J Med (2004) 351:1985-95. doi:10.1056/NEJMra041996

12. McAdams RM, McPherson RJ, Mayock DE, Juul SE. Outcomes of extremely low birth weight infants given early high-dose erythropoietin. J Perinatol (2013) 33:226-30. doi:10.1038/jp.2012.78

13. Thomas B, Eyssen M, Peeters R, Molenaers G, Van Hecke P, De Cock P, et al. Quantitative diffusion tensor imaging in cerebral palsy due to periventricular white matter injury. Brain (2005) 128:2562-77. doi:10.1093/brain/awh600

14. Chahboune H, Ment LR, Stewart WB, Rothman DL, Vaccarino FM, Hyder F, et al. Hypoxic injury during neonatal development in murine brain: correlation between in vivo DTI findings and behavioral assessment. Cereb Cortex (2009) 19:2891-901. doi:10.1093/cercor/bhp068

15. Volpe JJ. Brain injury in premature infants: a complex amalgam of destructive and developmental disturbances. Lancet Neurol (2009) 8:110-24. doi:10.1016/ S1474-4422(08)70294-1

16. Laughon M, O'Shea MT, Allred EN, Bose C, Kuban K, Van Marter LJ, et al. Chronic lung disease and the risk of developmental delay at two years of age in children born before 28 weeks postmenstrual age. Pediatrics (2009) 124:637-48. doi:10.1542/peds.2008-2874

17. O'Shea TM, Allred EN, Kuban KC, Dammann O, Paneth N, Fichorova R, et al. Elevated concentrations of inflammation-related proteins in postnatal blood predict severe developmental delay at 2 years of age in extremely preterm infants. J Pediatr (2012) 160:395-401. doi:10.1016/j.jpeds.2011.08.069

18. Rouse DJ, Hirtz DG, Thom E, Varner MW, Spong CY, Mercer BM, et al. A randomized, controlled trial of magnesium sulfate for the prevention of cerebral palsy. N Engl J Med (2008) 359:895-905. doi:10.1056/NEJMoa0801187

19. Doyle LW, Crowther CA, Middleton P, Marret S, Rouse D. Magnesium sulphate for women at risk of preterm birth for neuroprotection of the fetus. Cochrane Database Syst Rev (2009) 21(1):CD004661. doi:10.1002/14651858.CD004661. pub3

20. Maged M, Costantine MD. Effects of antenatal exposure to magnesium sulfate on neuroprotection and mortality in preterm infants: a meta-analysis. Obstet Gynecol (2009) 114:354-64. doi:10.1097/AOG.0b013e3181ae98c2

21. Ichiba H, Tamai H, Negishi H, Ueda T, Kim TJ, Sumida Y, et al. Randomized controlled trial of magnesium sulfate infusion for severe birth asphyxia. Pediatr Int (2002) 44:505-9. doi:10.1046/j.1442-200X.2002.01610.x

22. Ichiba H, Yokoi T, Tamai H, Ueda T, Kim TJ, Yamano T. Neurodevelopmental outcome of infants with birth asphyxia treated with magnesium sulfate. Pediatr Int (2006) 48:70-5. doi:10.1111/j.1442-200X.2006.02167.x

23. Bhat MA, Charoo BA, Bhat JI, Ahmad SM, Ali SW, Mufti MU. Magnesium sulfate in severe perinatal asphyxia: a randomized, placebo-controlled trial. Pediatrics (2009) 123:e764-9. doi:10.1542/peds.2007-3642

24. Gathwala G, Khera A, Singh J, Balhara B. Magnesium for neuroprotection in birth asphyxia. J Pediatr Neurosci (2010) 5:102-4. doi:10.4103/1817-1745.76094

25. Cetinkaya M, Alkan T, Ozyener F, Kafa IM, Kurt MA, Koksal N. Possible neuroprotective effects of magnesium sulfate and melatonin as both pre- and post-treatment in a neonatal hypoxic-ischemic rat model. Neonatology (2011) 99:302-10. doi:10.1159/000320643

26. Goñi-de-Cerio F, Alvarez A, Lara-Celador I, Alvarez FJ, Alonso-Alconada D, Hilario E. Magnesium sulfate treatment decreases the initial brain damage alterations produced after perinatal asphyxia in fetal lambs. J Neurosci Res (2012) 90:1932-40. doi:10.1002/jnr.23091

27. Stevenson TJ, Trinh T, Kogelschatz C, Fujimoto E, Lush M, Bonkowsky JL. Magnesium acts as a neuroprotectant for hypoxic pathfinding errors via EphrinB2a. PLoS Genet (2012) 8:e1002638. doi:10.1371/journal.pgen.1002638

28. Ball G, Srinivasan L, Aljabar P, Counsell SJ, Durighel G, Hajnal JV, et al. Development of cortical microstructure in the preterm human brain. Proc Natl Acad Sci U S A (2013) 110:9541-6. doi:10.1073/pnas.1301652110

29. Basu SK, Chickajajur V, Lopez V, Bhutada A, Pagala M, Rastogi S. Immediate clinical outcomes in preterm neonates receiving antenatal magnesium for neuroprotection. J Perinat Med (2011) 40:185-9. doi:10.1515/JPM.2011.094

30. Mitani M, Matsuda Y, Shimada E; Perinatal Research Network Group in Japan. Short- and long-term outcomes in babies born after antenatal magnesium treatment. J Obstet Gynaecol Res (2011) 37:1609-14. doi:10.1111/j.1447-0756.2011. 01583.x

31. Mishra OP, Fritz KI, Delivoria-Papadopoulos M. NMDA receptor and neonatal hypoxic brain injury. Ment Retard Dev Disabil Res Rev (2001) 7:249-53. doi:10.1002/mrdd.1034

32. Roman A, Desai N, Rochelson B, Gupta M, Solanki M, Xue X, et al. Maternal magnesium supplementation reduces intrauterine growth restriction and suppresses inflammation in a rat model. Am J Obstet Gynecol (2013) 208:383.e1-7. doi:10.1016/j.ajog.2013.03.001

33. Sugimoto J, Romani AM, Valentin-Torres AM, Luciano AA, Ramirez Kitchen CM, Funderburg N, et al. Magnesium decreases inflammatory cytokine production: a novel innate immunomodulatory mechanism. J Immunol (2012) 188:6338-46. doi:10.4049/jimmunol.1101765

34. Hosmer DW, Lemeshow S. Applied Logistic Regression. New York, NY: Wiley (2000). 392 p.

35. Sherwin CM, Balch A, Campbell SC, Fredrickson J, Clark EA, Varner M, et al. Maternal magnesium sulphate exposure predicts neonatal magnesium blood concentrations. Basic Clin Pharmacol Toxicol (2014) 114:318-22. doi:10.1111/ bcpt. 12166

36. Borja-Del-Rosario P, Basu SK, Haberman S, Bhutada A, Rastogi S. Neonatal serum magnesium concentrations are determined by total maternal dose of magnesium sulfate administered for neuroprotection. J Perinat Med (2013) 42:207-11. doi:10.1515/jpm-2013-0151

37. Conde-Agudelo A, Romero R. Antenatal magnesium sulfate for the prevention of cerebral palsy in preterm infants less than 34 weeks' gestation: a systematic review and metaanalysis. Am J Obstet Gynecol (2009) 200:595-609. doi:10.1016/j.ajog.2009.04.005

38. Beck S, Wojdyla D, Say L, Betran AP, Merialdi M, Requejo JH, et al. The worldwide incidence of preterm birth: a systematic review of maternal mortality and morbidity. Bull World Health Organ (2010) 88:31-8. doi:10.2471/BLT.08.062554

Conflict of Interest Statement: The authors declare that the research was conducted in the absence of any commercial or financial relationships that could be construed as a potential conflict of interest.

Received: 20 July 2014; accepted: 22 October 2014; published online: 05 November 2014.

Citation: Doll E, Wilkes J, Cook LJ, Korgenski EK, Faix RG, Yoder BA, Srivastava $R$, Sherwin CMT, Spigarelli MG, Clark EAS and Bonkowsky JL (2014) Neonatal magnesium levels correlate with motor outcomes in premature infants: a long-term retrospective cohort study. Front. Pediatr. 2:120. doi: 10.3389/fped.2014.00120

This article was submitted to Neuropediatrics, a section of the journal Frontiers in Pediatrics.

Copyright (C) 2014 Doll, Wilkes, Cook, Korgenski, Faix, Yoder, Srivastava, Sherwin, Spigarelli, Clark and Bonkowsky. This is an open-access article distributed under the terms of the Creative Commons Attribution License (CC BY). The use, distribution or reproduction in other forums is permitted, provided the original author(s) or licensor are credited and that the original publication in this journal is cited, in accordance with accepted academic practice. No use, distribution or reproduction is permitted which does not comply with these terms. 